\title{
Energy Efficiency in Buildings as an Air Quality Compliance Approach: Opportunities for the U.S. Department of Energy
}

\author{
Edward Vine \\ Environmental Energy Technologies Division \\ Ernest Orlando Lawrence Berkeley National Laboratory \\ Berkeley, CA 94720 \\ Prepared for the \\ Energy Efficiency and Renewable Energy's \\ Building Technology, State and Community Programs \\ U.S. Department of Energy
}

May 2002

This work was supported by the Assistant Secretary for Energy Efficiency and Renewable Energy, Office of Building Technology, State and Community Programs, of the U.S. Department of Energy under Contract No. DEAC03-76SF00098. 


\section{Acronyms}

\begin{tabular}{|c|c|}
\hline ACEEE & American Council for an Energy-Efficient Economy \\
\hline ALAPCO & Association of Local Air Pollution Control Officials \\
\hline Btu & British thermal unit \\
\hline CAA & Clean Air Act \\
\hline CAAA & Clean Air Act Amendments \\
\hline CCAP & Center for Clean Air Policy \\
\hline CFL & compact fluorescent lamp \\
\hline CRER & Conservation and Renewable Energy Reserve \\
\hline EE/RE & energy efficiency/renewable energy \\
\hline EERE-Buildings & $\begin{array}{l}\text { USDOE's Energy Efficiency and Renewable Energy's Building Technology, State and } \\
\text { Community Programs }\end{array}$ \\
\hline EIA & Energy Information Administration \\
\hline GCVTC & Grand Canyon Visibility Transport Commission \\
\hline GCVTR & Grand Canyon Visibility Transport Region \\
\hline GHG & greenhouse gas \\
\hline GWh & gigawatthour \\
\hline HERS & home energy rating system \\
\hline HVAC & heating, ventilation, and air-conditioning \\
\hline IPMVP & USDOE's International Performance Measurement and Verification Protocol \\
\hline $\mathrm{kW}$ & kilowatt \\
\hline $\mathrm{kWh}$ & kilowatthour \\
\hline MW & megawatt \\
\hline MWh & megawatthour \\
\hline NASEO & National Association of State Energy Officials \\
\hline NYSERDA & New York State Energy Research and Development Authority \\
\hline OTC & Ozone Transport Commission \\
\hline PUCT & Public Utility Commission of Texas \\
\hline RD\&D & research, development, and demonstration \\
\hline RFP & reasonable further progress \\
\hline ROP & rate of progress \\
\hline SEP & Supplemental Environmental Project \\
\hline SIP & State Implementation Plan \\
\hline STAPPA & State and Territorial Air Pollution Program Administrators \\
\hline TNRCC & Texas Natural Resource Conservation Commission \\
\hline UNFCCC & United Nations Framework Convention on Climate Change \\
\hline USDOE & U.S. Department of Energy \\
\hline USEPA & U.S. Environmental Protection Agency \\
\hline WIEB & Western Interstate Energy Board \\
\hline WRAP & Western Regional Air Partnership \\
\hline
\end{tabular}




\begin{abstract}
Increasing the energy efficiency of end-use equipment in the residential, commercial, and industrial sectors can reduce air pollution emissions and greenhouse gases significantly. Because energy efficiency is an effective means of reducing multi-pollutant emissions, it is important to ensure that energy efficiency is a fully engaged component of emission-reduction programs. However, while energy-efficiency measures are perceived by many stakeholders to be important options for improving air quality, some members in the air quality community are concerned about the ability of these measures to fit in a regulatory framework-in particular, the ability of emissions reductions from energy-efficiency measures to be real, quantifiable, certifiable, and enforceable. Hence, there are few air quality programs that include energy efficiency as a tool for complying with air quality regulations. This paper describes the connection between energy consumption and air quality, the potential role of energy-efficiency measures to meet air quality regulations, the barriers and challenges to the use of these measures in the air quality regulatory environment, and the potential role that the U.S. Department of Energy's (USDOE) Energy Efficiency and Renewable Energy's Building Technology, State and Community Programs (EERE-Buildings) could play in this area.

EERE-Buildings can play a very important role in promoting energy efficiency in the air quality community, in ways that are fully consistent with its overall mission. EERE-Buildings will need to work with other stakeholders to aggressively promote energy efficiency via multiple means: publications, analytical tools, pilot programs, demonstrations, and program and policy analysis and evaluation. EERE-Buildings and state energy officials have considerable experience in implementing and monitoring energy-savings projects, as well as in designing documentation and verification requirements of energy-efficiency improvements. The following lists suggest potential EERE-Buildings activities, grouped by whether EERE-Buildings would play a lead or supporting role.
\end{abstract}

\title{
EERE-Buildings in a Lead Role
}

- $\quad$ Develop protocols for quantifying emissions reductions from energy-efficiency building technologies and crediting them in State Implementation Plans (SIPs). For example, EERE-Buildings could support modeling activities and the use of the International Performance Measurement and Verification Protocol (IPMVP) for quantifying emissions reductions.

- $\quad$ Conduct analyses of the role of energy efficiency in integrated multi-pollutant reduction approaches. This study could be similar to that of the Interlaboratory Working Group (IWG 2000) and build upon the State and Territorial Air Pollution Program Administrators and Association of Local Air Pollution Control Officials (STAPPA/ALAPCO) study (1999), but focus on multiple air quality emissions and be conducted either nationally or regionally.

- Conduct research and disseminate information on emerging energy-efficiency technologies and highefficiency building codes and appliances that noncompliance areas could adopt if they want to use energy efficiency as a compliance method. For example, EERE-Buildings could conduct research on new 
technologies that could enable buildings to exceed present building codes by $60 \%$ or that could enable appliances to be $60 \%$ more efficient than national or state appliance standards.

- Provide financial support and technical assistance to state and regional air quality officials on projects, infrastructure development, education, and training dealing with energy efficiency.

- $\quad$ Encourage each state energy agency to report on the environmental performance of its energy-efficiency programs. For example, EERE-Buildings could examine existing and proposed contracts and agreements with state energy agencies to see if this recommendation could be required as part of the agreement.

- $\quad$ Recognize and reward energy-efficiency projects based on their emission-reduction benefits, as well as their energy-savings benefits. For example, a plaque honoring award winners could be presented at an annual awards ceremony.

\section{EERE-Buildings in a Supporting Role}

- Broaden awareness of energy-efficiency projects as legitimate opportunities for Supplemental Environmental Projects (SEPs). Possible activities include: (1) surveying the use of energy-efficiency projects in state SEPs; (2) adding language to SEP guidelines to explicitly encourage efficiency projects, (3) adding efficiency projects to state lists of proposed projects that violators can turn to for ideas when they are negotiating with environmental agencies about potential SEPs; (4) developing tables of certifiable emissions reductions from energy-efficiency technologies and services; (5) preparing reader-friendly descriptions of energy-efficiency projects that could be written into settlements as SEPs; and (6) establishing pools of SEP funds for pollution prevention.

- Improve existing air quality compliance programs: (1) redesign the Acid Rain Program, (2) expand setasides in $\mathrm{NO}_{\mathrm{x}}$ trading programs, and (3) create user-friendly procedures for including energy efficiency in SIPs generally.

- Design integrated multi-pollutant reduction approaches that explicitly include energy efficiency as a cornerstone in reducing emissions.

- Develop contingency strategies as part of SIPs, to address the uncertainties in projecting both emissionproducing activities and emissions reductions associated with energy-efficiency projects.

EERE-Buildings staff would not be able to do all of this work by itself. In fact, as noted above, EEREBuildings may be a supporting partner, rather than a leader. EERE-Buildings staff would need to work closely with federal, regional, state, and local organizations to leverage funding and technical assistance. For example, EEREBuildings could work with the U.S. Environmental Protection Agency (USEPA) federal land management agencies, and other USDOE offices and national laboratories (especially if energy efficiency is combined with renewable 
energy) at the federal level. At the regional level, EERE-Buildings could work with the Ozone Transport Commission, Western Interstate Energy Board, and the Western Regional Air Partnership. And at the state level, EERE-Buildings could work with state energy offices, state air quality/environmental agencies, state air regulators, and Native American organizations. State governments have often been the leaders in integrating environmental goals, and their inclusion in the design of federal programs is essential—both to leverage their expertise and to help ensure effective implementation. In all of these collaborations, EERE-Buildings should ensure the appropriate participation of both the private and non-governmental sectors. A workshop to discuss the roles and responsibilities of different partners should be conducted to start the collaboration process.

The USDOE is proposing a pilot program wherein it would collaborate with states to allocate a portion of the Energy Efficiency and Renewable Energy Division's R\&D dollars for energy-efficiency projects (Inside Energy 2002). This proposal is awaiting final approval. The work proposed in this paper could be one of the topics addressed in this pilot program. Many states should be interested in participating with USDOE in this important work.

In conclusion, the USDOE has a significant opportunity (as well as challenge) facing it. Building energy efficiency represents a cost-effective and efficient solution for addressing many of today's air quality problems. The mission of DOE and EERE does not need to change significantly to take advantage of this opportunity. By applying EERE-Buildings' expertise, tools, and resources to this societal issue, this investment will lead to long-term benefits in future years. 


\section{Table of Contents}

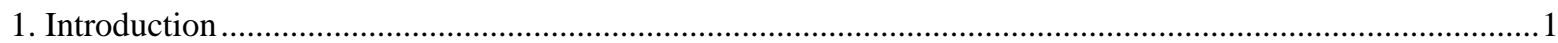

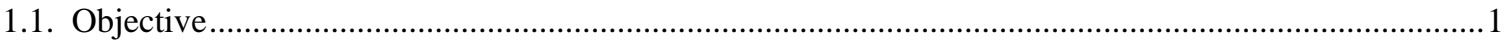

1.2. Energy Use, Energy Savings, and Air Quality ............................................................................

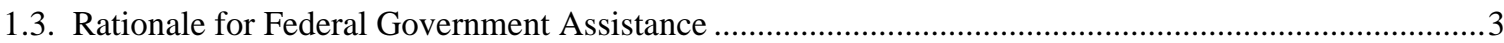

2. Air Quality Regulation and Energy Efficiency …….....................................................................................

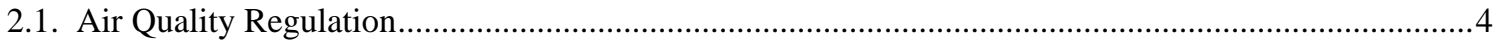

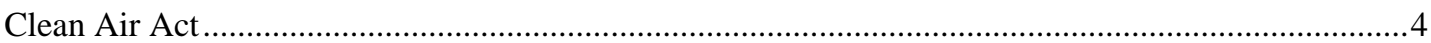

State Implementation Plans and Voluntary Programs .........................................................................

Acid Rain Program and CRER ……………………...................................................................

$\mathrm{NO}_{\mathrm{X}}$ SIP Call, $\mathrm{NO}_{\mathrm{X}}$ Budget Trading Program, and EE/RE Set-Asides.................................................

Regional Haze Rule ……………………………………............................................................. 10

Supplemental Environmental Projects Policy …………...........................................................................10

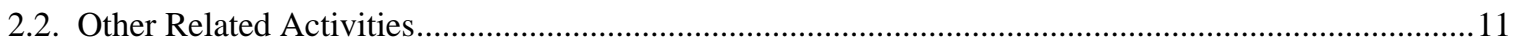

2.3. Promising Ways to Use Energy Efficiency to Meet Air Quality Regulations.........................................13

SEP-Funded Air Quality Fund Reserve for Energy Efficiency ................................................................13

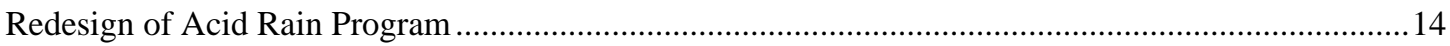

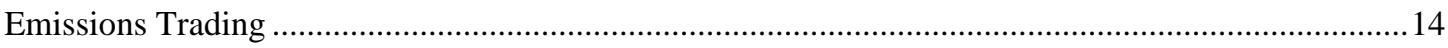

Multi-Pollutant Regulation ............................................................................................................. 15

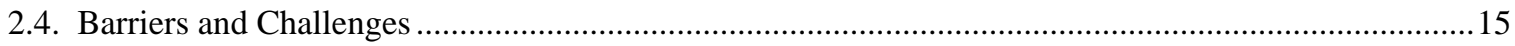

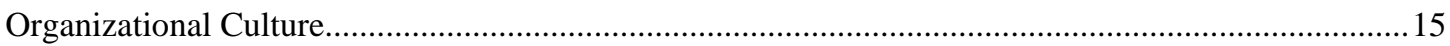

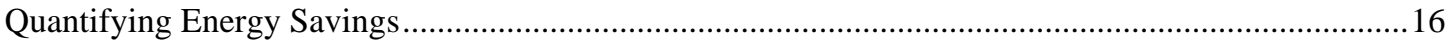

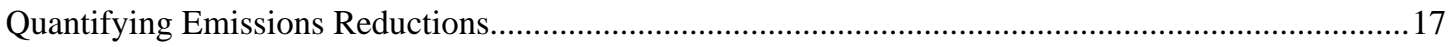

Accounting for Emissions Reductions Locations .................................................................................

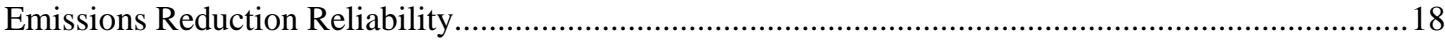

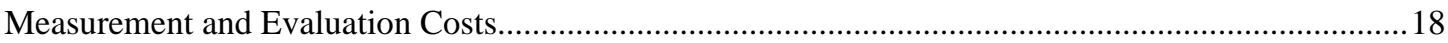

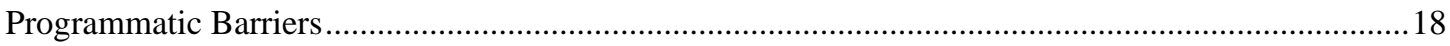

3. Opportunities for EERE-Buildings …………................................................................................... 


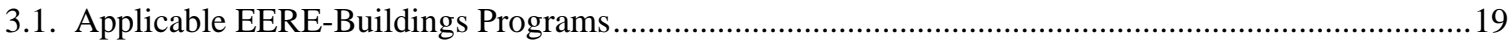

3.2. Possible Activities for EERE-Buildings .................................................................................21

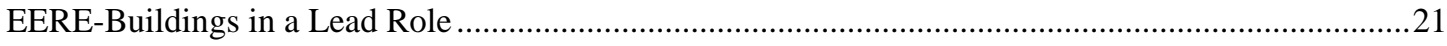

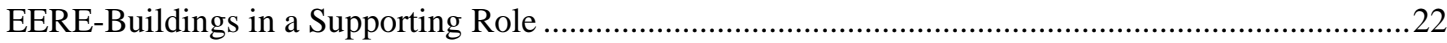

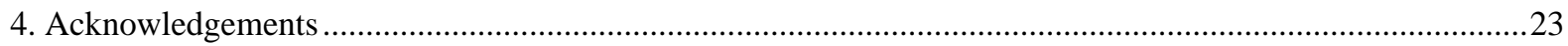

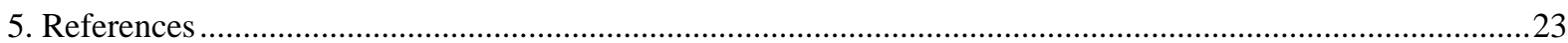

Tables

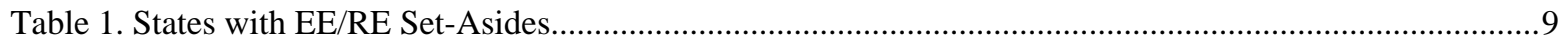




\section{Introduction}

\subsection{Objective}

Increasing the energy efficiency of end-use equipment in the residential, commercial, and industrial sectors can reduce air pollution emissions and greenhouse gases significantly. Because energy efficiency is an effective means of reducing multi-pollutant emissions, it is important to ensure that energy efficiency is a fully engaged component of emission-reduction programs. However, while energy-efficiency measures are perceived by many stakeholders to be important options for improving air quality, some members in the air quality community are concerned about the ability of these measures to fit in a regulatory framework - in particular, the ability of emissions reductions from energy-efficiency measures to be real, quantifiable, certifiable, and enforceable. Hence, there are few air quality programs that include energy efficiency as a tool for complying with air quality regulations. This paper describes the connection between energy consumption and air quality, the potential role of energy-efficiency measures to meet air quality regulations, the barriers and challenges to the use of these measures in the air quality regulatory environment, and the potential role that the U.S. Department of Energy's (USDOE) Energy Efficiency and Renewable Energy's Building Technology, State and Community Programs (EERE-Buildings) could play in this area.

This paper does not discuss two interrelated subjects: global climate change, and renewable energy and energy efficiency in other sectors. This paper does not discuss global climate change because there are neither regulations with associated compliance levels, nor enforcement or fines associated with greenhouse gas (GHG) emissions. ${ }^{1}$ Renewable energy or energy efficiency in other sectors (such as the transportation sector) are not examined because the primary audience for this paper is EERE-Buildings senior management engaged in the process of developing strategic and operational plans for their organization. ${ }^{2}$

\subsection{Energy Use, Energy Savings, and Air Quality}

The buildings sector (i.e., residential and commercial buildings) is a large user of energy-a significant portion of which is fossil fuel. The buildings sector was nearly the largest share (38\%) of energy consumption in the United States in 2000 (Energy Information Administration (EIA) 2001). ${ }^{3}$ Fossil fuels (primarily natural gas)

\footnotetext{
${ }^{1}$ It is worth noting that, unlike post-combustion pollution controls that generally reduce single pollutants, energy-efficiency measures reduce multiple air emissions, including $\mathrm{CO}_{2}$. Hence, the activities described in this paper, while not specifically addressing greenhouse gas (GHG) emissions, will help reduce GHG emissions and will help those states starting to address GHG impacts by recognizing the positive impacts of energy efficiency on carbon emissions. In fact, some states (e.g., Massachusetts and Oregon) are regulating $\mathrm{CO}_{2}$ emissions from power plants, and several localities have established GHG targets that could potentially be met with energy efficiency (e.g., Salt Lake City; San Francisco; Seattle; and Suffolk County, New York) (Center for Clean Air Policy 2002; Davis 2002).

${ }^{2}$ An analysis recently conducted by the National Renewable Energy Laboratory on renewable energy and the Clean Air Act was instrumental in providing critical information on a number of topics for this paper (Wooley and Morss 2001; Wooley, Morss, and Fang 2001).

${ }^{3}$ In 2000, total U.S. energy use was 98,498 trillion Btu (or 98.5 quads).
} 
represented approximately $70 \%$ and $85 \%$ of total energy consumption in the residential and commercial buildings sectors, respectively (ibid.). ${ }^{4}$

The buildings sector is a significant contributor of criteria pollutant $t^{5}$ emissions: e.g., in 1999, $48.5 \%$ of sulfur dioxide emissions were attributable to buildings energy service demand (45.5\% electric and 3\% on-site fossil fuel), and $21.5 \%$ of nitrogen oxide emissions were attributable to buildings energy service demand (17\% electric and $4.5 \%$ on-site fossil) (USEPA 2000a). In 1999, the buildings sector also accounted for $35 \%$ of carbon dioxide emissions (EIA 2001). ${ }^{6}$ These impacts are expected to continue in the future.

Energy efficiency in the buildings sector can play a significant role in reducing energy use and emissions beyond these projections. The residential and commercial sectors are characterized by a diverse array of energy uses and varying sizes and types of buildings in a wide range of climates; therefore, no single method can be used to improve energy efficiency. Rather, a broad array of technologies is available to reduce criteria pollutants, as well as greenhouse gases, through increasing end-use efficiency.

In one study (Alliance to Save Energy et al. 1997), the aggressive promotion of energy efficiency and renewable energy would result in the following benefits for the entire U.S. economy in 2010 (as compared to 1990 levels):

- $64 \%$ reduction in $\mathrm{SO}_{2}$ emission (dropping to 7 million tons per year)

- $27 \%$ reduction in $\mathrm{NO}_{\mathrm{x}}$ emissions (dropping to 15 million tons per year)

- $10 \%$ reduction in $\mathrm{CO}_{2}$ emissions (dropping to 1,207 million tons of carbon per year)

- reductions in other pollutants such as fine particles, toxic materials, and hydrocarbons

More recently, the American Council for an Energy-Efficient Economy (ACEEE) concluded that low-cost efficiency programs could displace approximately 64,000 megawatts (MW) of generation capacity within a decade nationwide (a 40\% reduction in the growth of peak demand), by focusing on just four key areas of opportunity (Nadel et al. 2000):

- Improving installation and maintenance of residential air conditioners

4 In 2000, residential energy use in the United States was 19.9 quads, and commercial energy use was 16.5 quads (includes electrical system energy losses). Since fossil fuel use accounts for approximately $70 \%$ of electricity generation, fossil fuels account for $84 \%$ of total residential energy consumption and $85 \%$ of total commercial energy consumption.

5 The U.S. Environmental Protection Agency (USEPA) has set national air quality standards for six principal criteria pollutants: carbon monoxide $(\mathrm{CO})$, lead, nitrogen dioxide $\left(\mathrm{NO}_{2}\right)$, ozone $\left(\mathrm{O}_{3}\right)$, particulate matter $\left(\mathrm{PM}_{10}\right)$, and sulfur dioxide $\left(\mathrm{SO}_{2}\right)$.

6 This estimate applies to residential and commercial buildings and excludes the industrial sector. Total carbon dioxide emissions from energy consumption were 1,510.8 million metric tons carbon equivalent. Tons of carbon equivalent can be converted to tons of carbon dioxide gas by multiplying by 3.667 . 
- Commissioning existing commercial buildings

- Higher efficiency standards for air conditioning

- Efficient commercial lighting systems

Finally, the air quality impacts from state energy-efficiency programs are starting to be estimated. For example, Efficiency Vermont, the nation's first energy-efficiency utility, calculated the following emission reductions over the life of the energy-efficiency measures installed in six energy-efficiency programs in 2000: 390 tons of $\mathrm{NO}_{\mathrm{X}} ; 1,035$ tons of $\mathrm{SO}_{2} ; 253,625$ tons of $\mathrm{CO}_{2}$; and 87 tons of particulates (Efficiency Vermont 2000). The New York Energy \$mart ${ }^{\mathrm{SM}}$ Program, the public benefits program in New York administered by the New York State Energy Research and Development Authority (NYSERDA), reported that its energy-efficiency programs will result in a decrease in the following air emissions, once available incentives were fully subscribed: 708 tons of $\mathrm{NO}_{\mathrm{X}}$; 1,150 tons of $\mathrm{SO}_{2}$; and close to 524,000 tons of $\mathrm{CO}_{2}$ (NYSERDA 2000). ${ }^{7}$

\subsection{Rationale for Federal Government Assistance}

In this section, we discuss the rationale for federal government assistance in specifically applying energyefficiency measures for pollution control. More specifically, we discuss the rationale for EERE-Buildings to become involved in the air quality arena. First, individuals and firms tend to overlook the impacts of their actions on society and the environment (i.e., environmental externalities). Thus, the federal government has an important role to play in promoting a clean environment. As discussed in the following pages, the federal government (under the Clean Air Act) has attempted to reduce the amount of air emissions from power producers and has started to develop more flexible options for meeting these regulations. Furthermore, energy efficiency is increasingly being seen by the public sector (and, hopefully, the private sector) as a cost-effective (and sometimes money-saving) option for responding to air quality needs. The federal government can provide information ${ }^{8}$ on energy efficiency to help states meet their air quality requirements. This information would also help the private sector by reducing the transaction costs associated with making decisions on energy-efficiency investments. Focusing on building energy efficiency is an appropriate strategy for federal government, because of: (1) the contribution of the building sector to emissions (see previous section), (2) the need to address the market barriers causing the sub-optimal use of energy-efficiency technologies, ${ }^{9}$ and (3) the extensive experience of federal energy managers and practitioners in analyzing and implementing energy-efficiency technologies and services in this sector.

7 Some states, like Texas, collect data on the emissions impacts of energy-efficiency programs, but do not publicly report them as an annual report (Taylor 2002).

${ }^{8}$ Information in the broadest sense: not only publications and analytical tools, but also pilot programs, demonstrations, and program and policy analysis, where needed.

${ }^{9}$ Examples of barriers in the buildings sector include: (1) lack of information on actual energy use of major appliances, (2) lack of supply of high energy-efficiency equipment from manufacturers, and (3) lack of available financing for investing in energyefficiency measures (Golove and Eto 1996). 
From a research, development, and demonstration (RD\&D) perspective, one of the key reasons for justifying a role for federal government in this area is that the potential aggregate benefits of research in this area are large, but the uncertainties are simply too great for the private sector to shoulder the full research costs. Many private organizations will realize economic gains from research on the energy efficiency/air quality nexus (as described at the end of this paper), but no single organization would realize enough economic gain to justify the full research costs by themselves. As discussed below, the federal government needs to be actively involved in conducting this research — but in collaboration with other public and private entities. Public-private RD\&D partnerships are usually the best arrangement, whenever possible. The advantages include leveraging of federal funding with private dollars and ensuring private-sector involvement in public goods activities. Near the end of this paper, we discuss in more detail what EERE-Buildings can offer in this area and the specific types of activities that EERE-Buildings should initiate.

\section{Air Quality Regulation and Energy Efficiency}

This section briefly describes key air quality regulations and examples (and opportunities) of how energy efficiency fits in this regulatory environment.

\subsection{Air Quality Regulation}

\section{Clean Air Act}

In the United States, the approach to air pollution control has evolved over several decades. Passed in 1963 and amended in 1970, 1978, 1990, and 1997, the federal Clean Air Act (CAA) forms the basis for most of the air quality measures in the United States. Under the Clean Air Act, the USEPA establishes national ambient air quality standards for pollutants that cause adverse effects to public health and the environment. The USEPA has set national air quality standards for six principal criteria pollutants (see footnote 5). States are required to establish the emissions targets needed to achieve and maintain compliance with these standards.

\section{State Implementation Plans (SIPs) and Voluntary Programs}

The Clean Air Act as amended requires states to develop State Implementation Plans (SIP) to demonstrate compliance with national ambient air quality standards. As part of the SIP process, each state must develop forecasts of economic activities to project the level of emissions and the control measures that will reduce emissions for each air quality control region that does not meet these standards (non-attainment areas). The state is responsible for enforcing the SIP once the USEPA reviews and approves it.

There are three generic opportunities for integrating energy efficiency and renewable resources in the SIP process (National Association of State Energy Officials (NASEO) 1998):

- $\quad$ Modification of the growth estimates or reference case projection of economic activity/emissions. The first step in preparing a SIP is to develop a reference case of emissions projections by identifying sources of emissions and their projected use or production. The baseline electricity demand projections are generally based upon a current public policy scenario assumption and/or past trends in electricity intensity. For example, the current public policy scenario generally includes 
current state building codes and federal appliance efficiency standards. The scenario also may include an explicit assumption concerning utility energy-efficiency programs. USEPA's growth estimates or reference case projections of economic activity and emissions can be modified if the change in growth is the result of clearly identified control strategies that can be shown to provide real, permanent, and quantifiable changes in growth (USEPA 1999). Therefore, documented and verifiable energy-efficiency improvements that exceed the current standards or baseline assumptions (or revisions to the current standards, such as an updated building code or a home energy rating system, or HERS) could be allowed as an adjustment to a state's growth estimates. ${ }^{10}$

- $\quad$ Design of additional programs or control measures to reduce emissions. Energy-efficiency measures can be explicit, cost-control measures in SIPs. For example, Texas analyzed building code practices and requested a $\mathrm{NO}_{\mathrm{x}}$ SIP credit for energy-efficiency practices. Based on an analysis of building code upgrades for the Dallas-Fort Worth area, Texas determined that the codes were real, enforceable, and quantifiable, therefore meeting the requirements for a SIP credit. The calculations resulted in a request to the USEPA for a credit of 0.5 tons per day of $\mathrm{NO}_{\mathrm{x}}$ for that particular measure, which the USEPA approved (Oehler 2002; Ozone Transport Commission (OTC) 2000).

The Texas Natural Resource Conservation Commission (TNRCC) and a group of interested stakeholders are developing an energy-efficiency guidance plan to determine SIP credits from a large set of energy-efficiency measures (Oehler 2002). This plan will formulate an equation by which TNRCC can take the reduction in energy demand that has occurred through the implementation of energy-efficiency measures and convert that amount into a quantity that can be used for SIP credit. They also plan to develop a method that private entities will be able to use to obtain similar credits. When ultimately approved by the USEPA, the Texas plan to use energy-efficiency measures to establish SIP credit is expected to set the precedent for facilitating the use of energy efficiency in the SIP process (Lubow 2002).

- Design of market-based programs and economic incentives, using the marketplace to achieve a given level of emission reduction (e.g., emissions budget or cap-and-trade program) at a lower cost. Energy-efficiency programs are fully eligible to receive emission credits or allowances, as discussed in the following pages.

One of the more important analytical and programmatic challenges is to make sure that energy-efficiency measures are not used more than once in the above approaches (to avoid "double counting"). For example, a program promoting energy-efficient appliances must be promoting appliances that are more efficient than baseline efficiencies (as reflected in the reference case) in order to receive air quality credits.

In light of the increasing cost associated with stationary source emission reductions and the difficulty of identifying additional stationary sources of emission reductions, the USEPA decided to stimulate innovative approaches

\footnotetext{
${ }^{10}$ Forty-seven out of fifty states now have at least one certified home energy rating system or one certified HERS consultant
} (National Renewable Energy Laboratory 2000). 
to emission reductions. In 2001, the USEPA introduced an innovative emission reduction approach where SIPs can explicitly include credits for voluntary stationary source emission reduction programs under Section 110 of the Clean Air Act (Seitz 2001). These programs must provide emission reductions that are quantifiable (and include procedures in the SIP to evaluate and verify over time the level of emission reductions actually achieved), surplus (i.e., emission reductions that are not already required to satisfy other Clean Air Act requirements for criteria pollutants), permanent, and enforceable (i.e., enforceable against the State, not against the source- that is, the State is responsible for ensuring that emission reductions take place). Examples cited include programs that reduce electricity usage and heat island programs. ${ }^{11}$ Because of the innovation involved in stationary source voluntary measures, the USEPA's inexperience in quantifying them, and the inability to enforce these measures against individual sources, the USEPA limited the amount of emission reductions likely to be achieved in this program to be $3 \%$ of needed reductions for "reasonable further progress" (RFP), "rate of progress" (ROP), or attainment demonstration purposes. ${ }^{12}$

The USEPA has expressed an intention of issuing a new, innovative measures SIP guidance document that could facilitate the greater use of energy-efficiency and renewable energy programs in the SIP process (Lubow 2002).

\section{Acid Rain Program and CRER}

Title IV of the Clean Air Act Amendments (CAAA) of 1990 set an annual national emissions cap of 8.9 million tons of $\mathrm{SO}_{2}$ (for utility emission sources above $25 \mathrm{MW}$ ) to be maintained through the issuance of emission allowances, beginning in 2000 with the implementation of Phase II. Power producers have various options for reducing $\mathrm{SO}_{2}$ emissions, including implementing energy-efficiency programs. $\mathrm{SO}_{2}$ allowances can be transferred, traded, and banked. ${ }^{13}$

As part of the cap, Congress created the Conservation and Renewable Energy Reserve (CRER) to encourage the use of energy efficiency and renewable energy as a compliance strategy (Morris and Shelby 1999; Wooley and Morss 2001; Wooley, Morss, and Fang 2001). Three hundred thousand $\mathrm{SO}_{2}$ bonus allowances (about $3 \%$ of the total emission cap of 8.9 million tons) were set aside to be allocated to utilities for energy-efficiency measures and renewable energy development. ${ }^{14}$ Qualifying utilities could then opt to either use the "bonus" credits generated through the CRER to meet their own requirements, or sell them on the open market. The intent was not only to encourage energy efficiency and renewable energy, but also to provide utilities with greater flexibility and control over designing the lowest-cost strategy for meeting the CAAA's requirements.

11 Heat island programs encourage activities that will reduce center-city temperatures during the summer (e.g., replacing roofs with Energy Star-labeled roof products or planting shade trees).

12 This is not $3 \%$ of an area's total emission inventory, but rather, $3 \%$ of the emissions beyond that point where the area reaches nonattainment. For example, if a State projects emissions in the attainment year to be 100 tons per day over the emissions needed to show attainment, the State could take credit for emission reductions from stationary source voluntary measures of up to 3 tons per day.

${ }^{13}$ Phase I of the Acid Rain Program, begun on January 1, 1995, established an allowable emission rate of $2.5 \mathrm{lb} / \mathrm{million}$ Btu (MMBtu) for affected sources (Wooley and Morss 2001; Wooley, Morss, and Fang 2001). Phase II began on January 1, 2000, with a $1.2 \mathrm{lb} / \mathrm{MMBtu}$ allowable emission rate; every unit (i.e., boiler) subject to the Clean Air Act will need to comply with the Phase II standard. In both phases, allowances are allocated to the affected plants according to a formula based on the baseperiod heat input rates. An allowance is an authorization to emit one ton of $\mathrm{SO}_{2}$. Because of allowance banking provisions and the existence of a sizable bank of allowances generated in Phase I, the amount of emissions for a given year can be different from 8.8 million tons (Kruger 2002; Morgan 2002).

${ }^{14}$ Of this amount, 60,000 tons were set aside just for renewables. 
All utilities with units affected by the CAAA were eligible to apply for these allowances. ${ }^{15}$ Applications could only be submitted after the energy savings have occurred and been verified. The verification process was left up to the states, but the USEPA developed a voluntary guidance document (Conservation Verification Protocols) to aid states in determining when reductions have occurred, and in ensuring that reported electricity reductions resulted directly from energy-efficiency measures (Meier and Solomon 1995; USEPA 1995 and 1996).

To date, CRER has had few applications for allowances. As of February 2002, only 48,868 allowances (approximately 16\% of the Reserve) have been awarded (Salpeter 2002); the deadline is still open to submit applications for previously realized energy savings until 2010. Key reasons for the poor participation are (Morris and Shelby 1999; Wooley, Morss, and Fang 2001):

- The market price of $\mathrm{SO}_{2}$ allowances turned out to be much lower than expected (for many utilities, it was cheaper to buy $\mathrm{SO}_{2}$ allowances in the market than to pursue allowances under the CRER program).

- The conversion factor for computing the number of allowances to be awarded—one allowance for 500 megawatthours (MWh), i.e., $0.004 \mathrm{lb}$ per kilowatthour (kWh) — was low, and discouraged participation in the program.

- Participation was limited to utilities (end users and energy service companies could not participate and claim allowances).

- The CRER statute and implementing regulations were developed when utilities were highly regulated. With the advent of electric industry restructuring, utilities are not aggressively pursuing energy-efficiency options and, therefore, have less incentive to participate in the CRER program.

- Electric utilities have been preoccupied with more important issues, such as restructuring, retail competition, selling off generating assets, and corporate mergers.

\section{$N O_{X}$ SIP Call, $\mathrm{NO}_{X}$ Budget Trading Program, and EE/RE Set-Asides}

Since 1990, both the USEPA and the states have also launched emissions-trading programs targeted primarily at reducing $\mathrm{NO}_{\mathrm{X}}$, a major precursor to the formation of ground-level ozone (smog) and acid rain. In September 1998, the USEPA promulgated a rule to address the regional transport of ground-level ozone. ${ }^{16}$ The final rule, commonly known as the $N \boldsymbol{O}_{X}$ SIP Call, required 22 states in the eastern United States and the District of Columbia to submit revised SIPs that

\footnotetext{
${ }^{15}$ There were time limits on eligible years for realized energy savings: utilities with at least one Phase I plant could only receive CRER allowances for energy savings realized from 1992 to 1994; all other utilities could receive allowances for energy savings realized from 1992 to 1999. As of 2000, the Acid Rain Program automatically provides credit to utilities for energy efficiency and renewable energy achievements in the form of saved $\mathrm{SO}_{2}$ allowances (even if the measures were undertaken by some other party) (Morgan 2002).

${ }^{16}$ The process of ozone and ozone precursors traveling from a source to downwind areas is referred to as ozone transport.
} 
addressed the regional transport of ground-level ozone through reductions in $\mathrm{NO}_{\mathrm{x}}\left(\right.$ Federal Register 1998) ${ }^{17}$ By reducing the emissions of $\mathrm{NO}_{\mathrm{X}}$, the actions directed by these SIPs will decrease the transport of ozone across state boundaries in the eastern half of the United States. The SIP Call requires emissions-reduction measures to be in place by May 1, 2004. The development of this program was a cooperative effort of the USDOE, USEPA, state energy offices, and state air quality regulators - and represented one of the first times that stakeholders had tried to work together to design a compliance strategy incorporating energy-efficiency benefits into air quality plans (Sharpless 2002).

The SIP Call rule aims to reduce total summertime (May 1 through September 30) emissions of $\mathrm{NO}_{\mathrm{x}}$ by about 28\% (1.2 million tons) beginning in the year 2004 in the 23 affected jurisdictions. To help the states achieve this goal, the SIP Call rule established the $\mathbf{N O}_{\mathbf{x}}$ Budget Trading Program, which will allow states to achieve more than $90 \%$ of the required emission reductions in a cost-effective manner (Wooley and Morss 2001; Wooley, Morss, and Fang 2001). The $\mathrm{NO}_{\mathrm{x}}$ Budget Trading Program comprises the $\mathrm{NO}_{\mathrm{x}}$ emission allowances that the USEPA has allocated on a per-state basis in the SIP Call region for the purpose of mitigating ozone transport in the summer months.

One of the options available to states in the $\mathrm{NO}_{\mathrm{x}}$ Budget Trading Program is the energy efficiency/renewable energy (EE/RE) set-aside—a pool of allowances that comes from within a state's $\mathrm{NO}_{\mathrm{X}}$ budget and is used to award energy-efficiency and renewable-energy projects in the state that reduce or displace electricity generation. ${ }^{18}$ The objectives of the set-aside are the following: (1) recognize the significant role that energy efficiency and renewable energy resources play in reducing pollution and achieving the nation's environmental goals; (2) reduce the total economic cost of meeting the proposed $\mathrm{NO}_{\mathrm{x}}$ cap; (3) provide greater flexibility in how state and local governments can meet their air quality attainment goals; and (4) reduce future $\mathrm{CO}_{2}$-related liabilities. Energy Efficiency/Renewable Energy set-aside allowances are intended to reward actions that result in a reduction in electricity generation at a core source (the generation site) or in supplanting the use of electricity from the grid. The set-aside option was initiated by the USEPA as an effort to help states include the emissions reductions achieved through voluntary actions, such as energy efficiency and renewable energy projects, in SIPs. After an initial SIP submittal, states develop a plan outlining how their $\mathrm{EE} / \mathrm{RE}$ set-aside will be implemented. The plan needs to answer several questions, including what protocols the state will use to measure and verify $\mathrm{EE} / \mathrm{RE}$ projects, and how the $\mathrm{NO}_{\mathrm{x}}$ emissions associated with the energy that is saved or displaced will be determined.

The USEPA developed two guidance documents for this program (USEPA 1999 and 2000b). ${ }^{19}$ In the first guidance document, the USEPA recommended that the set-aside pool of allowances range between 5-15\% of the state's total $\mathrm{NO}_{\mathrm{x}}$ Trading Program Budget for electricity generation (USEPA 1999). ${ }^{20}$ Also, the USEPA recommended that to be eligible for allowances, states should use the following criteria for determining whether projects are eligible (ibid.):

${ }^{17}$ In addition to this federal program, the states in the Northeast Ozone Transport Region have implemented their own $\mathrm{NO}_{\mathrm{X}}$ emissions-trading program in an effort to attain the federal standard for ozone in that region. In 1994, the states entered into a Memorandum of Understanding in which they agreed to enact regulations implementing a $\mathrm{NO}_{\mathrm{X}}$ cap-and-trade program. The program became effective in the Summer of 1999 and predates the federal program and will continue to do so until May 2004 when the SIP Call is expected to supersede it (Seidman 2002). Not all of the states that are part of the OTC Program area are part of the $\mathrm{NO}_{\mathrm{X}}$ Sip Call (e.g., New Hampshire) (Mercado 2002).

${ }^{18}$ The EE/RE set-asides replace the $3 \%$ voluntary stationary source emission reduction programs in those states that implement $\mathrm{EE} / \mathrm{RE}$ set-asides for the same pollutants and programs. However, states with EE/RE set-asides may have a voluntary stationary source program that addresses other pollutants or programs (Mercado 2000).

19 The USEPA is in the process of finalizing a draft of its third guidance document (on monitoring and verification) (Mercado 2000).

${ }^{20}$ This range is based on the potential for energy efficiency and renewable energy to prevent $\mathrm{NO}_{\mathrm{X}}$ emissions in the SIP Call region. 
- Reduce/displace electricity load from core source electricity generation units in the SIP Call region

- Not be required by federal government regulation

- Not be used to generate compliance or permitting credits otherwise in the SIP

- Be in operation in the year(s) for which it will receive allowances

- Reduce/displace energy during the summer ozone season

- Be measured and verified in accordance with the methods in this [USEPA's] guidance

- Translate into not less than one ton of $\mathrm{NO}_{\mathrm{x}}$ allowances, or be aggregated with other projects into one-ton increments of $\mathrm{NO}_{\mathrm{x}}$ allowances

In the second guidance document, the USEPA recommended a list of technologies that could potentially qualify for set-aside allowances, although it was up to each state to make the final determination of the actions that qualify (USEPA 2000b). They organized the technologies into three groups (lighting, HVAC and refrigeration, and motors and other technologies) and indicated which technologies were not eligible for this program. The USEPA further recommended that projects should be awarded allowances for at least three consecutive ozone control periods, and that verification of energy savings and displacements from projects receiving set-aside awards should occur annually. States could choose their own measurement and verification approach, although USDOE's International Performance Measurement and Verification Protocol (IPMVP) was listed as one of the available tools to use (USDOE 2001) (ibid.). ${ }^{21}$ The allowances would be available to end users of all types, including aggregators, vendors, and others. Eligible entities include commercial and industrial building owners and operators; energy service companies; home builders and associations; homeowners associations; federal, state, and local government agencies; commercial businesses; manufacturers; and other industrial users, as well as manufacturers leasing or selling energy-efficient equipment.

States were required to submit revised SIPs by September 30, 1999, and are required to implement their $\mathrm{NO}_{\mathrm{x}}$ SIP Call programs by May 1, 2003 (Wooley, Morss, and Fang 2001). In addition, states were required to achieve their overall $\mathrm{NO}_{\mathrm{X}}$ budgets by September 2007. Legal delays caused the new implementation date to be moved to May 2004 (ibid.). ${ }^{22}$

${ }^{21}$ The protocol can be downloaded via the World Wide Web at http://www.ipmvp.org. The IPMVP is discussed in more detail later in this paper. California and New York are using the IPMVP for certifying $\mathrm{kWh}$ reductions from energy-efficiency projects.

${ }^{22}$ The $\mathrm{NO}_{\mathrm{X}}$ SIP Call was challenged in court on various grounds. However, the Court of Appeals eventually rejected the challenge, and SIP submissions became due October 30, 2000. 
As shown in Table 1, at least six states have adopted EE/RE set-asides (Fontaine 2002; Indiana 2001; Western Interstate Energy Board (WIEB) 2002a).

Table 1. States with EE/RE Set-Asides

\begin{tabular}{|l|l|}
\hline Indiana & 1,079 allowances $\left(2 \%\right.$ of $\mathrm{NO}_{\mathrm{X}}$ budget) for 2004 and following years \\
\hline Maryland & 436 allowances $\left(3 \%\right.$ of $\mathrm{NO}_{\mathrm{X}}$ budget) for 2003 and following years) ${ }^{23}$ \\
\hline Massachusetts & 643 allowances $\left(5 \%\right.$ of $\mathrm{NO}_{\mathrm{X}}$ budget) for 2003 and following years \\
\hline New Hampshire ${ }^{24}$ & 445 allowances per year from 2000-2005 \\
\hline New Jersey & 410 allowances (5\% of $\mathrm{NO}_{\mathrm{X}}$ budget) for 2003 and following years \\
\hline New York & $\begin{array}{l}115 \text { allowances for } 1999 ; 1241 \text { allowances (3\% of } \mathrm{NO}_{\mathrm{X}} \text { budget) for } \\
2003 \text { and following years }\end{array}$ \\
\hline
\end{tabular}

Many of the states are still in the process of developing the program, especially the measurement and evaluation approach. The states do not have specific lists of eligible measures. Instead they provide general guidance. ${ }^{25}$ So far, there have been very few requests for allowances that have been set aside (Bielawa 2002; Fontaine 2002; McNevin 2002; Mosier 2002; Seidman 2002). The inclusion of energy-efficiency measures in these programs are not likely to be substantial until (1) an aggregator aggregates the small energy-efficiency projects and (2) the program becomes more heavily publicized (Fontaine 2002).

\section{Regional Haze Rule}

States are beginning to address visibility problems (regional haze) in national parks and wilderness areas throughout the country. Because power plant emissions of $\mathrm{SO}_{2}$ and $\mathrm{NO}_{\mathrm{x}}$ contribute to the formation of regional haze, these emissions may have to be further reduced to improve visibility in some areas. In response to the Clean Air Act, the USEPA issued regulations in 1980 to address visibility impairment from single sources, and in 1999 it issued the Regional Haze Rule to address visibility impairment on a regional level (Federal Register 1999). The rule, which will be implemented over 60 years, requires all 50 states to establish goals and emission-reduction strategies for improving visibility in the nation's 156 mandatory Class 1 national parks and wilderness areas. The regional haze regulations are goal-oriented, leaving states with considerable discretion to design and implement their own regional haze programs.

The Rule requires each state to prepare a SIP and includes a separate section (Section 51.309) that allows nine western states participating in the Grand Canyon Visibility Transport Commission (GCVTC) to implement a

${ }^{23}$ An amendment clarifying the Maryland $\mathrm{NO}_{\mathrm{X}}$ SIP Call is being developed and would allow renewable energy projects (but not energy efficiency ) to be included (Mosier 2002).

${ }^{24}$ New Hampshire is part of the OTC Program but not part of the $\mathrm{NO}_{\mathrm{X}}$ SIP Call.

${ }^{25}$ For example, in New Hampshire, "end-use efficiency projects" are those projects that: (1) are implemented by, or on behalf of, a consumer of electric power in New Hampshire; (2) reduce consumers' consumption of power; (3) were installed after May 1, 1999; (4) are in operation in the control period for which allowances from the EE/RE set-aside are claimed; and (5) correspond to no less than one ton of utility $\mathrm{NO}_{\mathrm{X}}$ emissions reductions either individually or when aggregated with other similar projects (New Hampshire 2002). 
regional approach to reducing haze. ${ }^{26}$ As part of this regional approach, these nine states are required to include in their SIPs a variety of information addressing energy efficiency, renewable energy, and economic development, including an outline of the programs and policies that each state will rely on to work towards meeting its goals. The state SIPs must be submitted to the USEPA no later than December 31, 2003. The Western Regional Air Partnership (WRAP) - the successor to the GCVTC-is responsible for submitting recommendations for implementing the regional haze program in the Grand Canyon Visibility Transport Region.

The Regional Haze Rule specifically addresses SIP requirements regarding air pollution prevention, and outlines specific information that is to be included in each SIP that addresses the use of energy-efficiency measures to prevent air pollution. For example, Section 309 of the Rule requires states to include in their SIPs a variety of information addressing energy efficiency, such as: (1) programs to preserve and expand conservation efforts; and (2) projections of the short- and long-term emissions reductions, visibility improvements, costs savings, and secondary benefits associated with energy-efficiency activities.

\section{Supplemental Environmental Projects Policy}

If the USEPA believes that an individual or company has failed to comply with federal environmental laws (including the Clean Air Act), the USEPA may initiate an enforcement action, usually resulting in individuals or companies paying cash penalties and being subjected to injunctive relief (i.e., actions needed to eliminate noncompliance, correct environmental damage, and restore the environment). The USEPA's Supplemental Environmental Projects (SEP) Policy encourages the use of environmentally beneficial projects as part of the settlement of an enforcement action (USEPA 1998 and 1999). States may also include SEPs in state case settlements. Supplemental Environmental Projects are activities that an entity undertakes in addition to those that are required to put it in compliance with environmental laws. Through SEPs, the settlement of an enforcement action can result in environmental and public health protections beyond those specifically required by law. The USEPA identified seven specific categories of projects that may qualify as SEPs; energy-efficiency projects could be included in three of them: pollution prevention, pollution reduction, and assessments and audits.

Supplemental Environmental Projects have existed since the early 1980s, and their use has increased steadily through the 1990s (USEPA 2001b). For example, while more than 200 SEPs were approved by USEPA in 1992, a total of 336 SEPs were agreed to as part of 197 federal settlement cases in fiscal year 1999. The total monetary value of these SEPs in 1999 was over \$230 million. Approximately one-half of these projects were classified as pollution prevention or pollution reduction activities.

A firm cited for an air quality violation could enact SEPs that reduce air emissions, and energy efficiency projects can be used for SEPs (Shepard 2001). For example, the State of Colorado has written into its SEP policy that pollution prevention, energy efficiency, and renewable energy projects should be considered (ibid.). A few energy-efficiency SEPs have been enacted in Colorado: e.g., (1) a Goodrich Corporation facility in Colorado used a SEP to fund an energy audit and the installation of energy-saving controls for lighting and HVAC equipment, (2) Colorado State University in Fort Collins converted incandescent exterior lighting to metal halide and compact fluorescent lamps (CFLs), and (3) the University of Colorado at Boulder upgraded insulation in a music building

26 The nine states are: Arizona, California, Colorado, Idaho, Nevada, New Mexico, Oregon, Utah, and Wyoming. The GCVTC was created by the 1990 Amendments to the Clean Air Act. 
(ibid.). Aside from these few examples, SEPs are a largely untapped mechanism for encouraging energy-efficiency projects, probably because the negotiations are often among lawyers unaware of the opportunities for promoting energy efficiency. As discussed below, EERE-Buildings could play an important role in this area. Furthermore, the USEPA has recently expressed an interest in promoting the greater use of energy efficiency and renewable energy programs within the SEP program (Lubow 2002).

\subsection{Other Related Activities}

The Ozone Transport Commission (OTC $)^{27}$ is currently funding a survey of planned and ongoing energyefficiency projects in OTC states and a compilation of detailed successful case studies (OTC 2001). Also, the OTC Technology and Innovations Committee is exploring options that states can pursue concerning new technologies and innovative policies for reducing air pollution.

With support from the Pew Center on Global Climate Change (Pew), the National Association of State Energy Officials (NASEO) is collecting data on state programs that deliver net emissions reduction and developing program summaries and case studies. Some programs were designed specifically to address climate change, but many were designed for other purposes, such as promoting water conservation (Pew 2002). Besides describing the programs and listing their greenhouse gas benefits, the case studies document how the programs were developed and funded, the challenges that were overcome to implement them, and the lessons learned along the way. Sources of further information are also provided. A few of the programs on the Pew Web site focus on energy efficiency.

The Western Interstate Energy Board (WIEB), an organization of 12 western states and 3 Canadian provinces, is sponsoring the SIP Guidebook Project (WIEB 2002). The guidebook will explain the opportunities and procedures for incorporating efficiency and renewable energy measures under Section 309 of USEPA's Regional Haze Rule. The guidebook will be based on the modeling being conducted under the Western Regional Air Partnership. This project will also consider options for compliance under Section 308, including: (1) modification of the growth estimates or reference case projection of economic activity/emissions; (2) design of additional programs or control measures to reduce emissions; and (3) design of market-based programs and economic incentives using emission markets to achieve a given level of emissions reduction.

The Western Regional Air Partnership (WRAP) ${ }^{28}$ is a collaborative effort of tribal and state governments and various federal agencies working to develop the technical and policy tools needed by the western states and tribes to comply with the USEPA's Regional Haze Rule. WRAP is sponsoring work on modeling the Western system impacts of renewable energy and energy-efficiency measures, and is in the process of developing recommendations regarding energy-efficiency and renewable energy programs (WRAP 2002).

27 The OTC was formed by Congress by the Clean Air Act Amendments of 1990 to help coordinate control planning of groundlevel ozone in the northeast and mid-Atlantic states. The OTC is comprised of government leaders and environmental officials from 12 northeast and mid-Atlantic states (Connecticut, Delaware, Maine, Maryland, Massachusetts, New Hampshire, New Jersey, New York, Pennsylvania, Rhode Island, Vermont, and Virginia) and the District of Columbia (which together compose the Ozone Transport Region), as well as the USEPA.

28 In 1997, western governors and tribal leaders created WRAP to implement the Grand Canyon Visibility Transport Commission's recommendations (see Regional Haze section). 
The State and Territorial Air Pollution Program Administrators (STAPPA) and Association of Local Air Pollution Control Officials (ALAPCO) have assessed strategies that simultaneously reduce conventional air pollution and greenhouse gases (STAPPA/ALAPCO 1999). One of the selected strategies was "reducing electricity consumption via improved end-use efficiency." The strategy of multi-pollutant regulation is discussed below.

The Center for Clean Air Policy (CCAP) has two projects that are closely related to the goal of building energy efficiency into air quality programs (Davis 2002). The first project seeks to encourage energy efficiency through the design of emissions trading programs under multi-pollutant cap-and-trade programs. The second project seeks to maximize emissions reductions associated with energy efficiency and renewable energy public benefit fund expenditures, including the quantification of emissions benefits. For this project, the Center will develop and implement prototype selection criteria that target energy efficiency and renewable energy technologies that maximize a variety of air emissions reductions.

To reinforce the market's recognition that environmental protection is one of the main reasons for the state to offer incentives for energy efficiency, the New York State Energy Research and Development Authority (NYSERDA) has split the incentives it pays for energy-efficiency projects into two distinct categories: one for energy savings and one for $\mathrm{NO}_{\mathrm{X}}$ reductions. ${ }^{29}$ New York's program, administered by NYSERDA, promotes standard performance contracting for commercial and industrial customers. This is a $\$ 20$ million program (running from July 1, 2001 to June 30, 2002, or until funds are fully committed) that offers a one-time payment to energy service companies of 10.5 cents to 28.8 cents per first-year $\mathrm{kWh}$ savings from energy-efficiency projects (NYSERDA 2001a). The $\mathrm{NO}_{\mathrm{x}}$ incentive is calculated at $\$ 4,000$ per ton of $\mathrm{NO}_{\mathrm{X}}$ emission reduction for each year of savings up to five years (up to $\$ 20,000$ of total incentive per ton) and amounts to about $5 \%$ of the total incentive for a given energy-efficiency project. The energy savings are verified by an energy service company. Although the $\mathrm{NO}_{\mathrm{x}}$ reduction incentive is only a small share of the overall incentive, it is an important early example of placing specific market valuation on the environmental benefit of projects. State officials hope this program will make energy services companies more aware of how $\mathrm{NO}_{\mathrm{X}}$ allowances can enhance the economic performance of their projects (Shepard 2001).

The program's success is demonstrated by the fact that approximately $90 \%$ of participants in the incentive program are requesting $\mathrm{NO}_{\mathrm{X}}$ incentives (Baldyga 2002). The program incentives are averaging about $25 \%$ of the total project cost, and the $\mathrm{NO}_{\mathrm{X}}$ component is about $4 \%$ of the incentive (Ahearn 2002). For the $2001 \mathrm{NO}_{\mathrm{X}}$ season (May 1 to September 30), savings for 31 projects totaled 15.5 million $\mathrm{kWh}$ and 11.6 tons of $\mathrm{NO}_{\mathrm{x}}$ emission reduction (ibid.).

The State of Texas is implementing a similar strategy, but through air quality legislation. In 2001, the Texas State Legislature passed SB 5, amending the Texas Emissions Reduction Plan to include an EnergyEfficiency Grant Program (Texas 2001). The Public Utility Commission of Texas (PUCT) will develop this grant program to promote energy efficiency and peak energy demand reductions, and the PUCT is required to provide an annual report that "quantifies the reductions of energy demand, peak loads, and associated emissions of air

\footnotetext{
${ }^{29}$ This program appears to be the only energy-efficiency program in the country that provides incentives directly for air quality benefits. There are other energy-efficiency programs (e.g., appliance recycling programs) that provide incentives for turning in old appliances (e.g., refrigerators and freezers), which lead to significant energy and environmental benefits.
} 
contaminants" (ibid., Sec. 386.205). The PUCT issued guidelines for this program in March, and applications will be accepted from March 26 to April 8, 2002. The total revenue available for the first year is $\$ 400,000$ (Gross 2002).

\subsection{Promising Ways to Use Energy Efficiency to Meet Air Quality Regulations}

This section provides examples of how energy efficiency can help to meet air quality regulations; these examples are conceptual and have yet to be tested. The four examples are (1) air quality fund reserves for energy efficiency, (2) redesign of the Acid Rain Program, (3) emissions trading, and (4) multi-pollutant regulation. The first two are redesigns of existing programs, while the other two examples are not yet part of any presently codified program. Because these opportunities are being explored, they represent good candidates for EERE-Buildings to actively participate in the design and implementation of these programs, either in a leading or supporting role, as discussed in Section 3.

\section{SEP-Funded Air Quality Fund Reserve for Energy Efficiency}

As noted previously, the use of supplemental environmental projects (SEPs) has increased since their inception, but energy efficiency is not a major component of SEPs. One of the principal reasons for this lack of use is a kind of "timing Catch 22." When energy-efficiency projects are about to be implemented, the funds are not available, or when the funds are available, a project developer may not be ready to use the funds. To make these funds more readily available for developers of energy-efficiency projects, a pool of funding that is explicitly targeted to energy efficiency needs to be created. For example, as their SEP, violators would pay into the pool, and the pool would, on its own schedule, award loans or grants to fund energy-efficiency options (Shepard 2001). As noted previously, one such SEP fund for energy-efficiency projects has already been initiated in Colorado.

\section{Redesign of Acid Rain Program}

There are serious limitations in the design of the Acid Rain Program for promoting energy efficiency and renewable energy. However, a more energy-efficiency-friendly Acid Rain Program could be redesigned ${ }^{30}$ by initiating the following types of measures: (1) Lower the $\mathrm{SO}_{2}$ cap, which may increase the price of allowances, making energy efficiency more attractive; (2) create a set-aside program to replace the CRER (similar to the set asides in the $\mathrm{NO}_{\mathrm{x}}$ cap-and-trade program); (3) change the $\mathrm{SO}_{2}$ allowance allocation method by favoring an outputbased system that allocates allowances based on the electricity output of the different generating plants without regard to the types of fuel used (in contrast to the existing program, which allocates emission allowances according to the heat input embodied in the fossil fuels); (4) phase out the existing allowance program in favor of an allowance auction system (the government caps emissions of one or more pollutants and then auctions the allowances needed to operate under the cap to the highest bidder); (5) use a simplified system for allocating allowances for several pollutants, using a traditional or output-based allocation scheme ("multi-pollutant regulation," see below); and (6) enable not only utilities, but also other parties (e.g., utility customers and energy services companies) to participate (Morris and Shelby 1999; Wooley, Morss, and Fang 2001). Discussions regarding federal multi-pollutant legislation (see below) may provide an opportunity for restructuring the Acid Rain Program in some of the ways proposed above.

30 Prior to redesign, an analysis of the positive and negative aspects of these proposals would need to be conducted, in order to show the environmental, economic, and programmatic costs and benefits. 


\section{Emissions Trading}

Emission markets appear to be working reasonably well for emitters that receive $\mathrm{SO}_{2}$ and $\mathrm{NO}_{\mathrm{x}}$ allowances, but with a few exceptions, energy efficiency has been unable to participate extensively in the clean air marketplace (Shepard 2001). Market rules could be restructured to allow the cleanest energy options to achieve financial rewards from emissions markets. For example, in national and regional cap-and-trade emission markets, allowances could be auctioned (see previous paragraph), and some of the proceeds of the auction could be dedicated to the development of energy-efficiency services. Additionally, more stringent caps may provide the needed incentive for power producers to seek energy-efficiency reductions from their customers, so they can comply with the emission budgets (see previous paragraph). Given the proper incentives, customers may provide sufficient energy savings, resulting in reductions in energy generation and emissions. Energy-efficiency set-asides would still be needed as part of capand-trade emission markets.

At least two other options for distributing allowances would favor energy efficiency and renewable energy. First, allowances could be allocated to all thermal sources on the basis of a standard emissions amount per unit of heat input. This would reward operators of clean thermal sources, because they would receive more allowances than they need to offset the emissions associated with their fuel input and could sell excess allowances. Second, allowances could be allocated to any generating source for each MWh of electricity production (an output-based system). Output-based allowance allocation systems will benefit energy-efficient sources. Energy-efficient sources that do not need the allowances will either have more excess allowances to sell or need to purchase fewer allowances than less-efficient sources. 


\section{Multi-Pollutant Regulation}

States and the federal government are beginning to investigate the feasibility and cost-effectiveness of various control technologies (including multi-pollutant control technologies) and strategies to further reduce emissions of $\mathrm{NO}_{\mathrm{x}}, \mathrm{SO}_{2}$, particulate matter, mercury, other toxics, and potentially $\mathrm{CO}_{2}$. The current approach of single-pollutant requirements is considered inefficient and ineffective, imposing unnecessarily high costs due to: (1) stranded capital investment from the installation of controls that later become obsolete when additional requirements are promulgated; (2) reduced lead time for complying with those requirements; (3) limited or nonexistent flexibility for emissions trading to allow cost-efficient control options; and (4) a reliance upon lengthy, expensive, and uncertain litigation to sort out regulatory ambiguity and compliance with the law (U.S. Office of the President 2002). There are currently a number of alternatives, serious proposals, and bills under discussion in the U.S. Senate and the House dealing with substantial reductions in emissions from the electricity sector (e.g., Senate Bill 556, the Clean Power Act of 2001, introduced by Senator Jeffords). Many of these bills involve multi-pollutant strategies to control various emissions from the electricity generation sector. If the control of greenhouse gases (particularly carbon dioxide) becomes a high priority for the United States, a strong multi-pollutant bill would be an important vehicle to address this issue.

On February 14, 2002, President George Bush proposed a multi-pollutant strategy ("The Clear Skies Initiative") that would reduce emissions of $\mathrm{SO}_{2}, \mathrm{NO}_{\mathrm{x}}$, and mercury (U.S. Office of the President 2002). Using a capand-trade program, the Initiative would establish national emissions limits for each pollutant, and allowances would be distributed to power producers. The power producers could trade allowances by reducing emissions and selling unneeded allowances in the market, or by buying more allowances in the market to meet emission limits. The role of energy efficiency was not discussed in the announcement of this program, but clearly power producers could implement energy-efficiency programs to reduce the amount of energy that needed to be produced, resulting in reduced emissions.

\subsection{Barriers and Challenges}

There are few air quality programs that include energy efficiency as a tool for complying with air quality regulations. And in those few examples, energy efficiency is not being used as much as it could be. This inattention to energy efficiency may be due to the newness of some of the innovative air quality programs described in this paper. Accordingly, as these programs mature, energy efficiency may become a more important feature of these programs. However, the perceived unimportance of energy efficiency is also due to cultural, technical, and programmatic barriers described in this section, some of which are being addressed by organizations around the country.

\section{Organizational Culture}

One of the key barriers is organizational culture. For example, energy and air quality program personnel represent different "cultures," use different "languages," and frequently have different perspectives on local and global concerns. For example, energy personnel assume that reductions in energy use reduce or displace new or existing energy production. In their minds, these hypothesized reductions or displacements of energy production translate directly into actual emission reductions. Historically, they have not concerned themselves with demonstrating where, when, or whether emissions reductions occur at actual, specified emissions sources. In 
contrast, air quality personnel focus on emissions sources to determine allowable emissions levels and emissions reductions. For them, reducing electricity demand in a non-attainment area does not necessarily translate into an emissions reduction within the airshed. For some air quality regulators, only reduced activity or lowered emissions rates at power plants located within the non-attainment area can qualify as emissions reductions in air compliance plans. This is reinforced because the emissions measurements are made at the point of production, and not at the point of ultimate use. In sum, what is measured and how it is accounted for in air compliance plans is a pivotal issue that must be resolved before air quality and energy officials can begin to identify new opportunities for energyefficiency improvements within air quality compliance strategies.

In the last few years, these discussions have been underway, particularly in response to the regulations described in the previous section. As noted above, USEPA and some regions are designing air quality programs that recognize energy efficiency as an important part of their air quality strategy. The cornerstone of their strategy to ensure that energy-efficiency measures are real, permanent, and enforceable is the creation of viable measurement and evaluation protocols. Many regions are relying on the USDOE's International Performance Measurement and Verification Protocol (IPMVP) for ensuring that actual energy savings will occur with the installation of energyefficiency measures. ${ }^{31}$ Furthermore, models are being designed that translate energy savings into emission reductions.

\section{Quantifying Energy Savings}

The challenge in properly quantifying the energy savings from energy-efficiency measures and programs is a technical barrier that is being addressed. In particular, present analyses need to address two key concerns: (1) those of energy officials concerned that the environmental officials' energy savings evaluation methods are flawed, and that they underrepresent total savings; and (2) those of air officials that need to ensure that the energy savings claimed are measurable, verifiable, and permanent. In the last 20 years, the evaluation of energy savings from energy-efficiency technologies and programs has developed into a vigorous, professional activity. ${ }^{32}$ As this field has matured, several protocols for measuring and verifying energy savings have been developed, e.g., USEPA's Conservation Verification Protocols (USEPA 1995), USDOE's International Performance Measurement and Verification Protocol (USDOE 2001), and others (e.g., Vine and Sathaye 1997, 1999, and 2000). These protocols are being used by energy services companies, utility companies, and the federal government.

For some air quality regulators, the measurement and verification of emission reductions from energyefficiency measures should have the same accuracy as a continuous emission monitoring device on the stack of a generator (Atcheson 2002). In an attempt to create comparable accuracy, as part of the $\mathrm{NO}_{\mathrm{x}}$ set-aside

\footnotetext{
${ }^{31}$ We explicitly mention the IPMVP because of its widespread use in the energy-efficiency and regulatory communities. North America's energy service companies have adopted the IPMVP as the industry standard approach to measurement and verification. States ranging from Florida to New York now require the use of the IPMVP for state-level energy efficiency retrofits. The Department of Energy's Federal Energy Management Program uses the IPMVP approach for energy retrofits in federal buildings. The California Public Utilities Commission recently required the use of the IPMVP as the principal basis for the measurement and evaluation of California's new energy-efficiency programs.

${ }^{32}$ For example, witness the papers, workshops, and panels on program evaluation presented at the International Energy Program Evaluation Conference (www.iepec.org), the American Council for an Energy-Efficient Economy's Summer Study on Energy Efficiency in Buildings (www.aceee.org), and the Association of Energy Service Professionals' Annual Conference (www.aesp.org).
} 
implementation strategy, the USDOE and USEPA are working together to "discount" energy-efficiency related reductions due to perceived uncertainty (ibid.). The "discounting" would typically result in a calculation of lowered energy savings and emission reductions as a result of measurement uncertainty, since initial estimates of savings and reductions are based on expectations and assumptions that are often different than what actually occurs in the field. ${ }^{33}$ The International Performance Measurement and Verification Protocol Adjustments Committee also recently examined five possible approaches for discounting energy savings that might serve as the basis for an international agreement, discussed the strengths and weaknesses of each approach, and discussed lessons learned from conducting this evaluation process (Vine et al. 2002).

\section{Quantifying Emissions Reductions}

Another technical barrier is the challenge of accurately quantifying the actual emissions reductions from energy-efficiency measures and programs (Morris and Shelby 1999; Vine and Sathaye 1999). Emissions reductions can be calculated in one of two ways: (1) if emissions reductions are based on fuel-use or electricity-use data, then default emissions factors can be used, based on utility or non-utility estimates ${ }^{34}$; or (2) emissions factors can be based on generation data specific to the situation of the project (e.g., linking a particular project on an hourly or daily basis to the marginal unit it is affecting). In contrast to default emission factors (method \#1), the advantage of using the calculated factors (method \#2) is that they can be specifically tailored to match the energy-efficiency characteristics of the activities being implemented by time of day or season of the year. ${ }^{35}$ However, this will inevitably require more expertise and money.

The quantification of emissions reductions is more challenging in those states and regions where significant improvements have been made to air quality, existing power plants have become more efficient and less dirty, and these same plants are getting cleaner (e.g., California) (Sharpless 2002). As a result, some individuals argue that the energy-efficiency benefits from an air quality perspective are marginal when looking at the contribution from power facilities versus other sources. They argue that the overall contribution of energy efficiency would be insignificant and more trouble than it is worth.

33 Measurement activities may sometimes lead to increased savings and emission reductions: for example, additional energyefficiency measures may have been installed that were not foreseen at the time of project design, or because the measurement and verification of energy-efficiency projects tend to increase actual energy savings, persistence of savings, and confidence in savings, so that the application of measurement and verification to efficiency projects should increase the emissions credits that are credited to energy-efficiency projects.

${ }^{34}$ The emission factors represent the basic conversion between energy consumption and generation of emissions. These factors are usually expressed in mass of emitted gas per unit of energy input (grams/Gigajoule), or sometimes in mass of gas per mass of fuel (grams/kilogram or grams/ton).

${ }^{35}$ For example, if an energy-efficiency project affects energy demand at night, then baseload plants and emissions will probably be affected. Since different fuels are typically used for baseload and peak capacity plants, then emission reductions will also differ. The calculations become more complex (but more realistic) if one decides to use the emission rate of the marginal generating plant (multiplied by the energy saved) for each hour of the year, rather than the average emission rate for the entire system (i.e., total emissions divided by total sales). For the more detailed analysis, one must examine the utility's existing expansion plan to determine the generating resources that would be replaced by saved electricity, and the emissions from these electricity-supply resources. 


\section{Accounting for Emissions Reduction Locations}

Accounting for the location of emissions reductions is an important barrier in some areas of the country. For example, with increasingly regional markets for electricity, a measure may decrease emissions from generating sources beyond the state borders or outside a non-attainment area. As an example, an energy-efficiency program in Utah might force the highest cost power producer in the Western Interconnection to go off-line. This plant might be a high-cost, polluting power producer in Los Angeles, and emission credit could be given in Los Angeles for promoting energy efficiency in Utah (Larson 2002). In some cases, distance may have a great impact, while in others, the impact may be small or of no consequence (Morris and Shelby 1999). In all events, the methodologies for estimating emission reduction benefits need to account for the relative importance of location, and reporting requirements need to make sure that "double counting" is not permitted.

\section{Emissions Reduction Reliability}

A key question for many parties is to determine if planned energy-efficiency measures would reduce peak demand sufficiently and with enough reliability to defer or obviate planned capacity expansion of the particular plant where emissions are being considered for displacement. If so, the deferred or replaced source would be the marginal expansion resource to be used as a baseline. This type of analysis may result in more accurate estimates of emissions reductions, but this method will be more costly and require expertise in utility system modeling. In addition, this type of analysis is becoming more difficult in those regions where the utility industry is being restructured: e.g., the supply of energy may come from multiple energy suppliers, either within or outside the utility service area. As noted above, several organizations are starting to address this issue through modeling.

\section{Measurement and Evaluation Costs}

The cost of conducting measurement and evaluation is perceived as a barrier for some program managers. This is particularly troublesome when measuring energy savings and emission reductions from small efficiency investments in order to receive credit under a cap-and-trade program, or as a control measure. These costs may often outweigh the benefit to a project sponsor (in the case of a cap-and-trade program) or the state (in the case of a control measure). Hence, there is a need to better recognize and reward the air quality benefits from these investments. Accordingly, as part of the negotiations in implementing the Kyoto Protocol, the Conference of Parties of the United Nations Framework Convention on Climate Change (UNFCCC) agreed to look at methods for facilitating energy-efficiency improvement projects that reduce energy consumption on the supply or demand side by up to the equivalent of $15 \mathrm{GWh}$ per year (UNFCCC 2001).

\section{Programmatic Barriers}

A final set of barriers is programmatic. First, energy-efficiency measures and programs are not being heavily promoted by air quality managers. There is a concern that, with increased marketing, existing staff would be inundated with requests, diverting them from their other responsibilities (Fontaine 2002). Second, there are no nationwide cap-and-trade programs, even though there are some regional programs to address ozone non-attainment. Third, the $\mathrm{NO}_{\mathrm{X}}$ SIP Call depends on the willingness of individual states to develop a cap-and-trade approach and include it in their SIPs; only a handful of states have developed such an approach. Fourth, in some programs (e.g., $\mathrm{EE} / \mathrm{RE}$ set-asides), energy-efficiency projects are too small and do not meet a program's eligibility requirements. As 
a result, an aggregator is needed to aggregate these smaller projects. However, there are few entities stepping forward to assume this role. Fifth, the availability of funds does not mean that energy-efficiency developers will automatically be able to use the funds-timing can be problematic, and the supply of funds and the demand for those funds are not always well matched. Sixth, states have no method for claiming credit for emission reductions from sources that are not regulated under their SIP (Mann 2002). For example, residential and small commercial consumers are stationary area sources that individually have emissions that are too small or are too numerous to be considered as individual point sources. These are accounted for collectively in emissions inventories by estimating emissions on an areawide basis (e.g., at a county level), and many (but not all) area sources are unregulated.$^{36}$ Thus, if emissions from unregulated area sources are reduced because of energy-efficiency measures, there is no mechanism for a state to know this. ${ }^{37}$

\section{Opportunities for EERE-Buildings}

\subsection{Applicable EERE-Buildings Programs}

The mission of EERE-Buildings is to develop, promote, and integrate energy technologies and practices to make residential and commercial buildings more efficient and affordable, and communities more livable. To accelerate the development and wide application of energy-efficiency measures, EERE-Buildings: (1) conducts $\mathrm{R} \& \mathrm{D}$ on technologies and concepts for energy efficiency, working closely with the building industry and with manufacturers of materials, equipment, and appliances; (2) promotes energy- and money-saving opportunities to both builders and buyers of homes and commercial buildings; (3) works with state and local regulatory groups to improve building codes, appliance standards, and guidelines for efficient energy use; and (4) provides support and grants to states and communities for deployment of energy-efficient technologies and practices.

The current portfolio of programs in EERE-Buildings is diverse and contains many programs and tools that could be used for promoting energy efficiency to the air quality community. EERE-Buildings can provide the needed expertise and resources to help air quality officials incorporate energy efficiency into their air quality plans, as the following examples illustrate. Not all energy-efficiency technologies are equal in their effects on emissions. The magnitude of the emissions benefits from energy efficiency depends on many factors, including the total amount of energy generated and the timing of the energy impacts. For example, energy-efficiency projects that displace coal combustion have a greater impact on a variety of air emissions than those that displace natural gas or other types of generation. Similarly, some technologies are more effective in reducing base load (e.g., highefficiency equipment), whereas others are more attractive for peak-load reduction (e.g., thermal storage and energy management systems). If the base loads and peak loads are based on fossil fuels, then emissions can be reduced; if

\footnotetext{
${ }^{36}$ When a regulation does exist, it is likely to apply to a fuel supplier, not to individual consumers. An example would be a rule that requires fuel suppliers to sell fuels that contain less than a specified amount of sulfur (Mann 2002).

${ }^{37}$ The methodology for accounting for area source emissions is relatively crude (Mann 2002). In general, fuel consumption by all point sources (e.g., electric utility generating plants) is subtracted from a state level estimate of fuel consumption (typically from Energy Information Administration (EIA) reports or state energy offices), and the difference is apportioned to counties and smaller areas using population, employment, or another surrogate for actual fuel consumption. Thus, the only data from which changes in emissions from these sources can be tracked are the EIA reports and forecasts that are published. To the extent that EIA's future energy consumption forecasts reflect the impacts of energy-efficiency measures, they would be accounted for in the emissions inventories.
} 
they are based on clean energy (e.g., hydroelectric or natural gas), the emission benefits may be marginal. Hence, it is premature to provide a specific list of energy-efficiency technologies or services for each air quality program: that task would best be left to the key stakeholders in a particular geographic area.

The EERE-Buildings' Office of Building Research and Standards leads a comprehensive effort to establish minimum efficiency codes, standards, and guidelines that lay the groundwork for reduced energy use and lower operating costs. As discussed previously, these codes and standards form the baseline for determining whether energy savings are additional to what is forecasted and help to determine potential energy savings. As part of this Office, the Building Standards and Guidelines Program helps code and building industry organizations to upgrade model energy codes and helps states to adopt and implement these models. In addition, the Lighting and Appliance Standards Program develops test procedures and minimum efficiency standards for residential appliances and commercial equipment. These programs are relevant, because new and improved building and appliance standards and codes lead to real, permanent, and enforceable reductions in energy use.

The Energy Star ${ }^{\circledast}$ program is a voluntary program sponsored by USDOE and USEPA and focuses on educating consumers about the benefits of high-efficiency home appliances, consumer electronics, office equipment, windows, lighting, and building materials. The Energy Star label, which identifies high-efficiency appliances, equipment, and building components, is now widely recognized and is showing up on a growing range of products for home and business. These products include televisions, VCRs, personal computers, copiers, clothes washers, dishwashers, refrigerators, air conditioners, lighting fixtures, windows, doors, and skylights. The Energy Star program has been an important feature of many utility-sponsored energy-efficiency programs around the country.

Another relevant program is the Rebuild America Program, which is a voluntary network of community partnerships determined to reduce energy costs by saving energy locally. This program provides access to technical experts, training, guidance materials, and software; local and regional resources; peer exchange networks; and public recognition. This program focuses on five building sectors: private commercial, state and local governments, $\mathrm{K}-12$ schools, universities and colleges, and public and assisted housing.

Another pertinent EERE-Buildings program is the State Energy Program, which provides grants to leverage non-federal resources and allows the states to tailor programs to their local needs. In this program, special project grants promote the adoption of innovative, high-potential energy technologies developed by USDOE's end-use sector research program. This research program is conducted with partners in all areas of the U.S. building industry, along with academia, community organizations, state governments, and national laboratories. The R\&D portfolio concentrates on two areas: building components (building envelope elements, equipment, and appliances) and building systems integration (which takes into account the interactions of individual components, materials, and equipment systems within buildings).

One of the major goals of the State Energy Program's Strategic Plan for the $21^{s t}$ Century is to "maximize collaboration among State agencies and communities to realize the increased benefits that can be obtained through the interrelationships among energy, the environment, and the economy" (USDOE 2000). As part of USDOE's efforts to support the states in implementing this plan, USDOE awarded competitive grants in 2001 to 11 states for projects that illustrate ways in which energy offices can work successfully with state offices dealing with environmental quality. For example, a project in Utah is focused on making Utah air and energy officials aware of the opportunity to use energy-efficiency and renewable energy measures to meet the requirement of the regional 
haze rule and providing resource information sufficient to prepare state implementation plans that incorporate them as strategies for reducing haze-causing emissions (Lambert 2002).

\subsection{Possible Activities for EERE-Buildings}

EERE-Buildings can play a very important role in promoting energy efficiency in the air quality community in ways that are fully consistent with its overall mission. EERE-Buildings will need to work with other stakeholders to aggressively promote energy efficiency via multiple means: publications, analytical tools, pilot programs, demonstrations, and program and policy analysis and evaluation. EERE-Buildings and state energy officials have considerable experience in implementing and monitoring energy-savings projects, as well as in designing documentation and verification requirements of energy-efficiency improvements. The following lists suggest potential EERE-Buildings activities, grouped by whether EERE-Buildings would play a lead or supporting role.

\section{EERE-Buildings in a Lead Role}

- Develop protocols for quantifying emissions reductions from energy-efficiency building technologies and crediting them in SIPs. For example, EERE-Buildings could support modeling activities and the use of the IPMVP protocol for quantifying emissions reductions.

- $\quad$ Conduct analyses of the role of energy efficiency in integrated multi-pollutant reduction approaches. This study could be similar to that of the Interlaboratory Working Group (IWG 2000) and build upon the STAPPA/ALAPCO study (1999), but focus on multiple air quality emissions and be conducted either nationally or regionally.

- $\quad$ Conduct research and disseminate information on emerging energy-efficiency technologies and highefficiency building codes and appliances that noncompliance areas could adopt if they want to use energy efficiency as a compliance method. For example, EERE-Buildings could conduct research on new technologies that could enable buildings to exceed present building codes by $60 \%$ or that could enable appliances to be $60 \%$ more efficient than national or state appliance standards.

- Provide financial support and technical assistance to state and regional air quality officials on projects, infrastructure development, education, and training dealing with energy efficiency. For example, EEREBuildings could develop a guide on the best case studies evaluating energy-efficiency projects.

- $\quad$ Encourage each state energy agency to report on the environmental performance of its energy-efficiency programs (e.g., NYSERDA 2001 and Efficiency Vermont 2000). For example, EERE-Buildings could examine existing and proposed contracts and agreements with state energy agencies to see if this recommendation could be required as part of the agreement. 
- Recognize and reward energy-efficiency projects based on their emission-reduction benefits, as well as their energy-savings benefits. For example, a plaque honoring award winners could be presented at an annual awards ceremony.

\section{EERE-Buildings in a Supporting Role R3 $^{38}$}

- Broaden awareness of energy efficiency projects as legitimate opportunities for Supplemental Environmental Project (SEP) projects. Possible activities include: (1) surveying the use of energy efficiency projects in state SEPs; ${ }^{39}$ (2) adding language to SEP guidelines to explicitly encourage efficiency projects, (3) adding efficiency projects to state lists of proposed projects that violators can turn to for ideas when they are negotiating with environmental agencies about potential SEPs; (4) developing tables of certifiable emissions reductions from energy-efficiency technologies and services; (5) preparing readerfriendly descriptions of energy-efficiency projects that could be written into settlements as SEPs; and (6) establishing pools of SEP funds for pollution prevention.

- Improve existing air quality compliance programs: (1) redesign the Acid Rain Program, (2) expand setasides in $\mathrm{NO}_{\mathrm{X}}$ trading programs, and (3) create user-friendly procedures for including energy efficiency in SIPs generally.

- Design integrated multi-pollutant reduction approaches that explicitly include energy efficiency as a cornerstone in reducing emissions.

- Develop contingency strategies as part of SIPs, to address the uncertainties in projecting both emissionsproducing activities and emissions reductions associated with energy-efficiency projects.

EERE-Buildings staff would not be able to do all of this work by itself. In fact, as noted above, EEREBuildings may be a supporting partner, rather than a leader. EERE-Buildings staff would need to work closely with federal, regional, state, and local organizations to leverage funding and technical assistance. For example, EEREBuildings could work with the USEPA, federal land managers, and other USDOE offices and national laboratories (especially if energy efficiency is combined with renewable energy) at the federal level. At the regional level, EERE-Buildings could work with the Ozone Transport Commission, Western Interstate Energy Board, and the Western Regional Air Partnership. And at the state level, EERE-Buildings could work with state energy offices, state air quality/environmental agencies, state air regulators, and Native American organizations. State governments have often been the leaders in integrating environmental goals, and their inclusion in the design of federal programs is essential-both to leverage their expertise and to help ensure effective implementation. In all of these collaborations, EERE-Buildings should ensure the appropriate participation of both the private and nongovernmental sectors. A workshop to discuss the roles and responsibilities of different partners should be conducted to start the collaboration process.

${ }^{38}$ Most likely, the USEPA or a state air quality agency will take the lead role.

39 The USEPA does not track SEPs that are included in state enforcement actions, unless the state is a co-plaintiff in a federal enforcement action (Cavalier 2002). 
The USDOE is proposing a pilot program wherein it would collaborate with states to allocate a portion of the Energy Efficiency and Renewable Energy Division's R\&D dollars for energy-efficiency projects (Inside Energy 2002). This proposal is awaiting final approval. The work proposed in this paper could be one of the topics addressed in this pilot program. Many states should be interested in participating with USDOE in this important work.

In conclusion, the USDOE has a significant opportunity (as well as challenge) facing it. Building energy efficiency represents a cost-effective and efficient solution for addressing many of today's air quality problems. The mission of DOE and EERE does not need to change significantly to take advantage of this opportunity. By applying EERE-Buildings' expertise, tools, and resources to this societal issue, this investment will lead to long-term benefits in future years.

\section{Acknowledgements}

I would like to thank all of the people who provided information for this paper and all of the following people for reviewing earlier drafts of this document: John Atcheson, Bill Becker, David Boomsma, Stacey Davis, Bill Dean, Art Diem, Jerry Dion, Cathy Ghandehari, Theresa Gross, Stan Hadley, Kim Heroy-Rogalski, Larry Kinney, Jon Koomey, Joe Kruger, Faith Lambert, Tom McNevin, Satish Kumar, Doug Larson, Judy Lubow, Chuck Mann, Edgar Mercado, Rick Morgan, Andy Nicholls, Judy Odoulamy, Brad Oehler, Marylynn Placet, Jan Sharpless, Carol Tombari, Steve Wiel, and Mark Wilson. This work was supported by the Assistant Secretary for Energy Efficiency and Renewable Energy, Office of Building Technology, State and Community Programs, of the U.S. Department of Energy under Contract No. DE-AC03-76SF00098. The opinions expressed in this paper are those of the author and do not necessarily represent the views of the U.S. Department of Energy.

\section{References}

Ahearn, J. 2002. Personal communication with John Ahearn (NYSERDA), February 19, 2002.

Alliance to Save Energy, American Council for an Energy-Efficient Economy, Natural Resources Defense Council, Tellus Institute, and Union of Concerned Scientists. 1997. "Energy Innovations: A Prosperous Path to a Clean Environment," Alliance to Save Energy, Washington, D.C.

Atcheson, J. 2002. Personal communication with John Atchson, U.S. Department of Energy, March 7, 2002.

Baldyga, T. 2002. Personal communication with Todd Baldyga (NYSERDA), February 20, 2002.

Bielawa, B. 2002. Personal communication with Bob Bielawa (New York Department of Environmental Conservation), February. 19, 2002.

Cavalier, B. 2002. Personal communication with Beth Cavalier (USEPA), March 13, 2002.

Center for Clean Air Policy (CCAP). 2002. "State and Local Climate Actions - January 2001 through February 2002, Interim Summary,” Updated March 21, 2002, Center for Clean Air Policy, Washington, DC.

Davis, S. 2002. Personal communication with Stacey Davis (Center for Clean Air Policy), March 22, 2002.

Efficiency Vermont. 2000. “Annual Report 2000,” Efficiency Vermont, Burlington, Vt. 
Energy Information Administration (EIA). 2000. "Analysis of Strategies for Reducing Multiple Emissions from Power Plants: Sulfur Dioxide, Nitrogen Oxides, and Carbon Dioxide," U.S. Department of Energy, Washington, D.C.

Energy Information Administration (EIA). 2001. “Annual Energy Review 2000,” U.S. Department of Energy, Washington, D.C.

Federal Register. 1998. "Finding of Significant Contribution and Rulemaking for Certain States in the Ozone Transport Assessment Group Region for Purposes of Reducing Regional Transport of Ozone - Final Rule (40 CFR Parts 51, 72, 75, and 96),” 63(207): 57356-57538 (October 27, 1998).

Federal Register. 1999. "Regional Haze Regulations - Final Rule (40 CFR Part 51),” 64(126): 35714-35774 (July 1, 1999).

Fontaine, J. 2002. Personal communication with Joe Fontaine (New Hampshire Department of Environmental Services), February 14, 2002.

Golove, W. and J. Eto. 1996. "Market Barriers to Energy Efficiency: A Critical Reappraisal of the Rationale for Public Policies to Promote Energy Efficiency, LBNL-38059, Lawrence Berkeley National Laboratory, Berkeley, Calif.

Gross, T. 2002. Personal communication with Theresa Gross (Public Utility Commission of Texas), February 26 and March 6, 2002.

Indiana 2001. "Title 326 Air Pollution Control Board, Final Rule, $\mathrm{NO}_{\mathrm{x}}$ SIP Call," June 6, 2001, Indiana Department of Environmental Management. Web page: http://www.IN.gov/idem/air/standard/Sip.

Inside Energy. 2002. "States Would Help Direct R\&D Funding Under Proposed DOE Pilot," February 18, p. 12.

Interlaboratory Working Group (IWG), 2000. "Scenarios for a Clean Energy Future," LBNL-40533, Lawrence Berkeley National Laboratory, Berkeley, CA and ORNL-444, Oak Ridge National Laboratory, Oak Ridge, Tenn.

Kruger, J. 2002. Personal communication with Joe Kruger (USEPA), March 14, 2002.

Lambert, F. 2002. Personal communication with Faith Lambert (USDOE), April 19, 2002.

Larson, D. 2002. Personal communication with Doug Larson (Western Interstate Energy Board), March 7, 2002.

Lubow, J. 2002. Personal communication with Judy Lubow (USDOE detailee), March 11 and 20, 2002.

Mann, C. 2002. Personal communication with Chuck Mann (USEPA), March 20 and 22, 2002.

McNevin, T. 2002. Personal communication with Tom McNevin (New Jersey Department of Environmental Protection), February 27, 2002.

Meier, A. and B. Solomon. 1995. "The EPA's Protocols for Verifying Savings from Utility Energy-Conservation Programs," Energy: The International Journal 20(2): 105-115 (1995).

Mercado, E. 2002. Personal communication with Edgar Mercado (USEPA), March 22, 2002.

Morgan, R. 2002. Personal communication with Rick Morgan (USEPA), March 11 and 13, 2002.

Morris, C. and P. Shelby. 1999. "Recognizing Efficiency and Renewable Energy Under a Cap and Trade Program," Center for Clean Air Policy, Washington, D.C. 
Mosier, R. 2002. Personal communication with Randy Mosier (Maryland Department of Energy), February 25, 2002.

Nadel, S., F. Gordon, and C. Neme. 2000. "Using Targeted Energy Efficiency Programs to Reduce Peak Electrical Demand and Address Electric System Reliability Problems," American Council for an Energy-Efficient Economy, Washington, D.C.

National Association of State Energy Officials (NASEO). 1998. "State Implementation Plans for Air Quality: A Primer," National Association of State Energy Officials, Washington, D.C.

National Renewable Energy Laboratory (NREL). 2000. "National Status Report: Home Energy Rating Systems and Energy-Efficient Mortgages," NREL, Golden, CO.

New Hampshire. 2002. "Chapter Env-A $3200 \mathrm{NO}_{\mathrm{x}}$ Budget Trading Program," New Hampshire Code of Administrative Rules.

New York State Energy Research and Development Authority (NYSERDA). 2000. "New York Energy \$mart" Program, Evaluation and Status Report, Interim Report, NYSERDA, Albany, N.Y.

New York State Energy Research and Development Authority (NYSERDA). 2001a. "Commercial/Industrial Performance Program. Standard Performance Contracting Program Opportunity Notice (PON No. 624-01), NYSERDA, Albany, N.Y.

New York State Energy Research and Development Authority (NYSERDA). 2001b. "New York Energy \$mart ${ }^{\mathrm{SM}}$ Program, Evaluation and Status Report, Quarterly Report, June 2001,” NYSERDA, Albany, N.Y.

Oehler, B. 2002. Personal communication with Brad Oehler (Texas Natural Resource Conservation Commission), February 26 and March 12, 2002.

Ozone Transport Commission (OTC). 2000. "Energy Efficiency and Energy Conservation," Ozone Transport Commission, Technology and Innovations Committee, Washington, D.C.

Ozone Transport Commission (OTC). 2001. "Request for Proposals to Provide Technical Services: Survey of State Clean Power and Energy Efficiency Projects and Options for Clean Power/Energy Efficiency Program Implementation and Integration," RFP 01-1T, Ozone Transport Commission, Washington, D.C.

Pew Center on Global Climate Change (Pew) 2002. "State and Local Net Greenhouse Gas Emission Reduction Programs," Web site: www.pewclimate.org/states

Salpeter, A. 2002. Personal communication with Alex Salpeter (USEPA), February 23, 2002.

Sharpless, J. 2002. Personal communication with Jan Sharpless (consultant), March 22, 2002.

Seidman, N. 2002. Personal communication with Nancy Seidman (Massachusetts Department of Environmental Protection), February 14 and March 13, 2002.

Seitz, J. 2001. "Incorporating Voluntary Stationary Source Emission Reduction Programs into State Implementation Plans - Final Policy," memorandum of January 19, 2001, Office of Air Quality Planning and Standards, USEPA, Washington, D.C.

Shepard, M. 2001. "Green Money: Compensating Efficiency and Renewable Energy for their Environmental Benefits," ER-01-10, E Source, Boulder, Colo. 
State and Territorial Air Pollution Program Administrators (STAPPA) and Association of Local Air Pollution Control Officials (ALAPCO). 1999. "Reducing Greenhouse Gases and Air Pollution: A Menu of Harmonized Options, Final Report," STAPPA and ALAPCO, Washington, D.C.

Taylor, D. 2002. Personal communication with Dub Taylor (Texas State Energy Office), March 18, 2002.

Texas State Legislature. 2001. “S.B. No. 5, Legislative Session 77R,” Enrolled, June 15, 2001.

UNFCCC. 2001. "Implementation of the Buenos Aires Plan of Action: Adoption of the Decisions Giving Effect to the Bonn Agreements. Draft Decisions Forwarded for Elaboration, Completion, and Adoption. Work Programme on Mechanisms (Decisions 7/CP.4 and 14/CP.4). Proposal by the President. Addendum. Draft Decision CP.7 (Article 12). Modalities and Procedures for a Clean Development Mechanism as Defined in Article 12 of the Kyoto Protocol,” FCCC/CP/2001/L.24/Add.2. Nov. 9, 2001. Web site: www.unfccc.de.

U.S. Department of Energy (USDOE). 2000. "State Energy Program Strategic Plan for the $21^{\text {st }}$ Century," USDOE, Washington, D.C.

U.S. Department of Energy (USDOE). 2001. "International Performance Measurement and Verification Protocol, Concepts and Options for Determining Energy and Water Savings, Volume 1," USDOE, Washington, DC. Web site: www.ipmvp.org.

U.S. Environmental Protection Agency (USEPA). 1995. "Conservation and Verification Protocols, Version 2.0," EPA 430/B-95-012, USEPA, Washington, D.C.

U.S. Environmental Protection Agency (USEPA). 1996. "The User's Guide to the Conservation and Verification Protocols, Version 2.0,” EPA 430/B-96-002, USEPA, Washington, D.C.

U.S. Environmental Protection Agency (USEPA). 1998. "EPA Supplemental Environmental Projects Policy," May 1, 1998, USEPA, Washington, D.C.

U.S. Environmental Protection Agency (USEPA). 1999. "EPA's Supplemental Environmental Projects Policy: Questions and Answers for the Practitioner," USEPA, Washington, D.C.

U.S. Environmental Protection Agency (USEPA). 2000a. "National Air Pollutant Emission Trends, 1900-1998," USEPA, Washington, D.C.

U.S. Environmental Protection Agency (USEPA). 2000b. "Creating an Energy Efficiency and Renewable Energy Set-Aside in the $\mathrm{NO}_{\mathrm{X}}$ Budget Trading Program: Establishing a Set-Aside," USEPA, Washington, D.C.

U.S. Environmental Protection Agency (USEPA). 2001a. "Creating an Energy Efficiency and Renewable Energy Set-Aside in the $\mathrm{NO}_{\mathrm{x}}$ Budget Trading Program: Designing the Administrative and Quantitative Elements," USEPA, Washington, D.C.

U.S. Environmental Protection Agency (USEPA). 2001b. "Beyond Compliance: Supplemental Environmental Projects," EPA 325-R-01-001, Office of Enforcement and Compliance Assurance, USEPA, Washington, D.C.

U.S. Office of the President. 2002. "Executive Summary - The Clear Skies Initiative," issued by President Bush on February 14, 2002. Web site: www.whitehouse.gov/news/releases/2002/02/clearskies.html. 
Vine, E. and J. Sathaye. 1997. "The Monitoring, Evaluation, Reporting, and Verification of Climate Change Mitigation Projects: Discussion of Issues and Methodologies and Review of Existing Protocols and Guidelines,” LBNL-40316. Lawrence Berkeley National Laboratory, Berkeley, Calif.

Vine, E. and J. Sathaye. 1999. "Guidelines for the Monitoring, Evaluation, Reporting, Verification, and Certification of Energy-Efficiency Projects for Climate Change Mitigation," LBNL-41543. Lawrence Berkeley National Laboratory, Berkeley, Calif. Web site: http://eetd.lbl.gov/ea/ccm/ccPubs.html.

Vine, E. and J. Sathaye. 2000. "The Monitoring, Evaluation, Reporting, Verification, and Certification of EnergyEfficiency Projects," Mitigation and Adaptation Strategies for Global Change, 5(2): 189-216.

Vine, E., G. Kats, J. Sathaye, and H. Joshi. 2002. "International Greenhouse Gas Trading Programs: A Discussion of Measurement and Accounting Issues," Energy Policy, forthcoming.

Western Interstate Energy Board (WIEB). 2002a."States with Set-Aside for EE/RE in $\mathrm{NO}_{\mathrm{x}}$ Budget Rules." Web site: www.westgov.org/wieb/sipguide/state setasides.htm.

Western Interstate Energy Board (WIEB). 2002b."State Implementation Plan (SIP) Guidebook Project." Web site: www.westgov.org/wieb/sipguide/sip1.htm.

Western Regional Air Partnership (WRAP). 2002. Web site: www.wrapair.org.

Wooley, D. and E. Morss. 2001. "The Clean Air Act Amendments of 1990: Opportunities for Promoting Renewable Energy,” NREL/SR-620-29448, National Renewable Energy Laboratory, Golden, CO.

Wooley, D., E. Morss, and J. Fang. 2001. "The Clean Air Act and Renewable Energy: Opportunities, Barriers, and Options," NREL/CP-620-29654, National Renewable Energy Laboratory, Golden, CO 